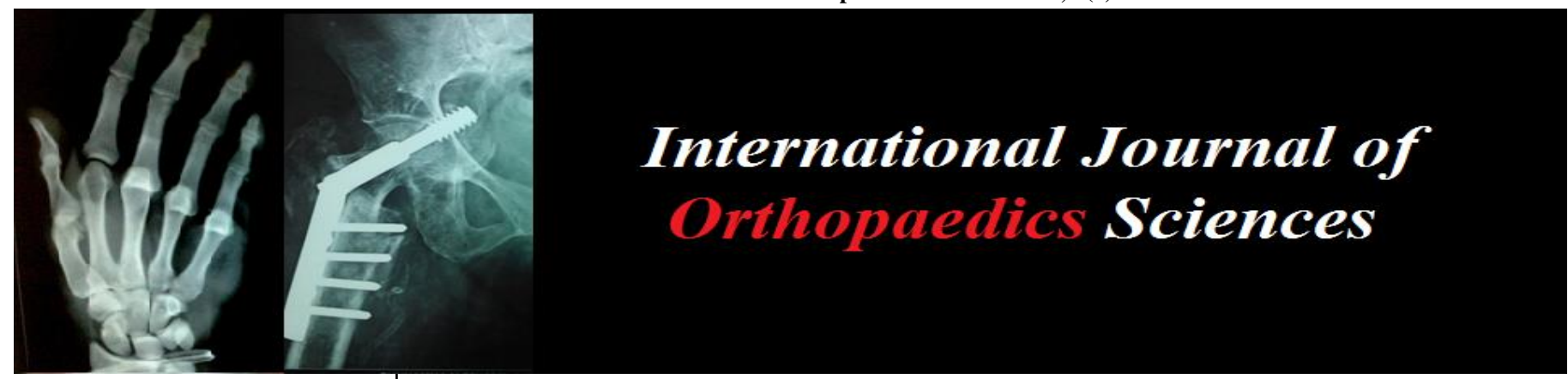

ISSN: $2395-1958$

IJOS 2019; 5(1): 369-371

(C) 2019 IJOS

www.orthopaper.com

Received: 07-01-2019

Accepted: 12-02-2019

\section{Dr. Maulik R Jhaveri}

Nri Boys Hostel Sumandeep

Vidyapeeth Campus, Piparia,

Waghodiya, Vadodara, Gujarat,

India

\section{Dr. Parth N Rathi}

Nri Boys Hostel Sumandeep

Vidyapeeth Campus, Piparia,

Waghodiya, Vadodara, Gujarat,

India

\section{Dr. Jay V Turakhiya}

Nri Boys Hostel Sumandeep

Vidyapeeth Campus, Piparia,

Waghodiya, Vadodara, Gujarat,

India

Dr. Prasanna N Shah

Nri Boys Hostel Sumandeep

Vidyapeeth Campus, Piparia,

Waghodiya, Vadodara, Gujarat,

India

Dr. Paresh P Golwala

Nri Boys Hostel Sumandeep

Vidyapeeth Campus, Piparia,

Waghodiya, Vadodara, Gujarat, India

\section{Correspondence}

Dr. Parth N Rathi

Nri Boys Hostel Sumandeep

Vidyapeeth Campus, Piparia,

Waghodiya, Vadodara, Gujarat,

India

\section{Foreign body removal from volar aspect of wrist joint: A rare case report}

\author{
Dr. Maulik R Jhaveri, Dr. Parth N Rathi, Dr. Jay V Turakhiya, Dr. \\ Prasanna N Shah and Dr. Paresh P Golwala
}

DOI: https://doi.org/10.22271/ortho.2019.v5.i1g.62

\section{Abstract}

Penetrating injuries to the hand are a common occurrence in the emergency room, and embedment of foreign bodies is suspected in many of these cases. We are presenting a case of 56 year old female with 9 days old injury on dorsal aspect of wrist with pointed shrapnel, penetrating through the dorsal aspect of lower one third of forearm located on volar aspect. Foreign body removed by small 3-4 cm incision on volar aspect of forearm locating object under IITV. Post operative patient had significant pain relief and free movement of wrist joint without pain.

Keywords: Foreign Body, Hand, Wrist, shrapnel

\section{Introduction}

More than 11 million patients are seen annually in emergency departments for traumatic wounds and lacerations. Nearly one third of these wounds involve the fingers, hand, or wrist. Additionally, a retained foreign body (FB) is present or strongly suspected in over $10 \%$ of the cases. Some foreign bodies are easy to detect or result in direct injury to vital structures, whereas others can remain asymptomatic and go unnoticed. The failure to treat or diagnose retained foreign bodies in the hand is among the top ten claims for most malpractice carriers, resulting in the fifth highest amount of indemnity awards to patients.

In general, current literature states that neurovascular (or potential) injury, tendon laceration, cosmetic deformity, functional impairment, and chronic pain are indications for wound exploration and foreign body removal. Contraindications to removal include deep embedding or inaccessibility, unacceptable iatrogenic risks to neurovascular structures during the retrieval process, minute size, inert material, and asymptomatic presentation $[1,14,20]$.

At our institution, embedded foreign bodies in the wrist and hand are generally treated acutely in the emergency department by removal of those that are easily visible and accessible. Foreign bodies are removed in the operating room only if it is encountered as part of a broader procedure necessitating general anesthesia to repair other injured structures.

\section{Material and Method}

56 year old female presented with complaint of pain in distal part of forearm and restricted movement of wrist joint since 9 days. On examination $2 \mathrm{~cm}$ suture mark present on dorsal aspect forearm and swelling and tenderness present on volar aspect of forearm. Wrist joint movements were restricted due to pain which was aggravated on extreme of dorsiflexion. Xray of wrist joint suggestive of radio-opaque foreign object on volar part of forearm and in between radius and ulna. Small $3 \mathrm{~cm}$ (approximately size of foreign body) incision was made on volar aspect of forearm; site of incision was decided under IITV. Flexor carpii radialis tendon was retracted. Blunt dissection was done to find foreign body and it was held with artery forceps and removed. Foreign body was $2 * 3 \mathrm{~cm}$ sharp metallic chip. Skin closure was done in sterile manner. 


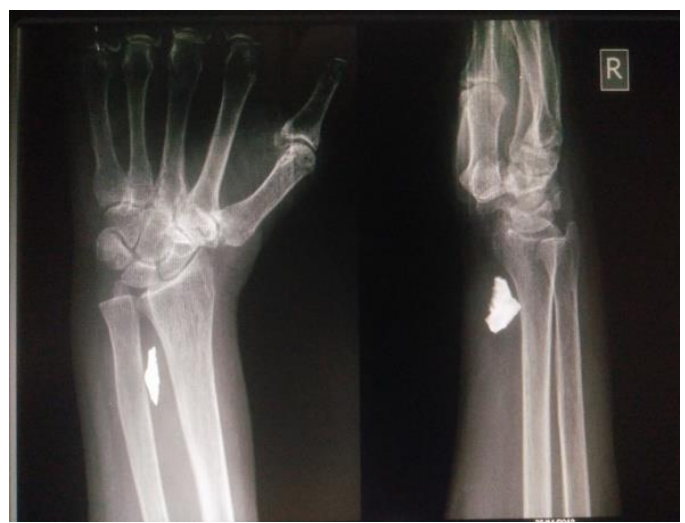

Pre-Operative X-Ray

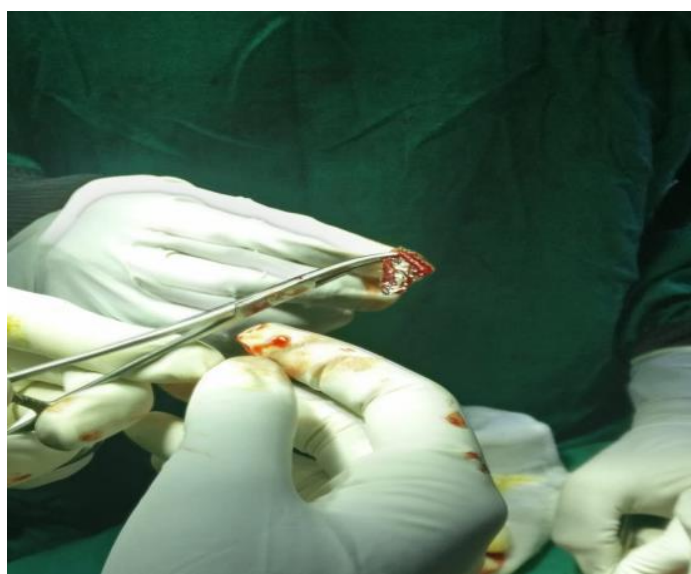

Foreign Body

\section{Discussion}

Foreign bodies may incite a variety of soft tissue infections, including local wound infection, cellulitis, abscess formation, lymphangitis, tenosynovitis, bursitis, and osteomyelitis. A foreign body rarely remains within a tendon sheath for prolonged time. In such cases, delay of the diagnosis occurs due to forgotten preceding injury. Therefore, complete medical history should be obtained. Imaging may be helpful to localize the metallic implant material when the history is not clear.

The size of the foreign body, moreover its anatomic location might determine clinical manifestations. A big foreign body cannot remain inside a synovial sheath, because it destroys the sheath and displaces into the surrounding tissues. Whereas a small foreign body may enter into the sheath of a tendon at the time that the puncture wound occurs, or it may work its way into the sheath from the adjacent tissues as a result of chronic inflammation and erosion of the sheath.

The decision to remove a deeply embedded foreign body depends on the object's size, location, composition, accessibility and any expected mechanical and inflammatory effects. However, most foreign bodies in the hands should be removed due to the potential risk of nerve and tendon injury. The proper approach for deeply embedded foreign bodies should include adequate anesthesia, a bloodless field, proper retracting of the wound edges and spreading deeper tissues for an extensive visualization ${ }^{[8,9]}$.

In conclusion, patient's history and laboratory-imaging results should be considered to get a good clue for the primary diagnosis of foreign body injuries.

In terms of the management, prompt exploration in the operating room is mandated in all cases of deep penetrating

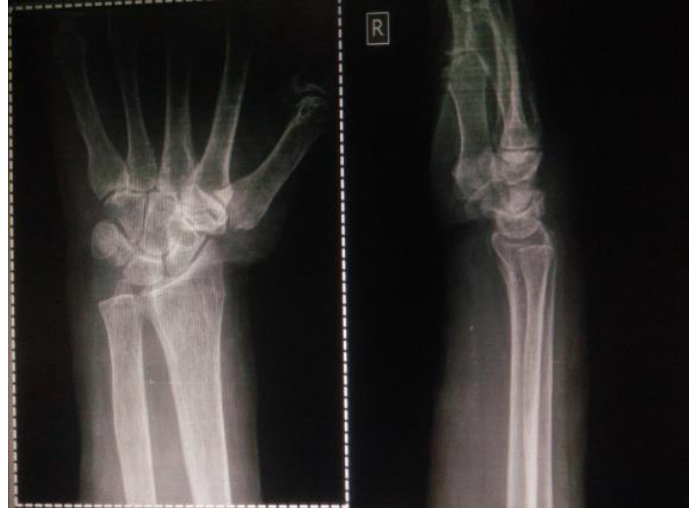

Post-Operative X-Ray

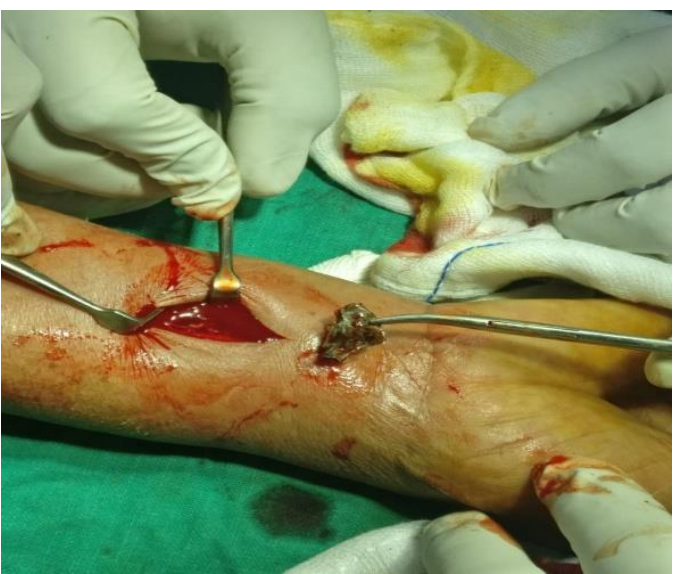

Intra-Operative Image

wrist trauma, if for no other reason, to debride the devitalized tissue (if any present) and to extensively irrigate the wound, ions before rushing to remove the foreign body. We should try to save as many structures as we can. It is important to remember that a sharp foreign body of even a very small diameter has the potential to seriously injure a wrist structure, especially if the foreign body is not fixed but is mobile. In these cases it can potentially cause a subcutaneous avulsion or laceration of a wrist structure while the external wound may be a small punctuate injury. Maintaining a stable position of the wrist during clinical and radiologic assessment in the emergency department is critical. Even in the cases of no obvious clinical signs of injury, blind removal of deep foreign bodies of the wrist is inappropriate and may potentially cause more injury to the underlying structures or delay and compromise operative exploration. During exploration, planning of the incision is crucial and the incision should be performed so as to maximize the exposure to the potentially injured areas. The foreign body should be removed only after most, if not all, of the involved structures have been visualized and that is especially important for the vascular structures. Tetanus prophylaxis is warranted for patients with these injuries.

\section{References}

1. DeBoard RH, Rondeau DF, Kang CS, Sabbaj A, McManus JG. Principles of basic wound evaluation and management in the emergency department. Emerg Med Clin North Am. 2007; 25(1):23-39. doi: 10.1016/j.emc.2006.12.001.

2. Hollander JE, Singer AJ, Valentine S, Henry MC. Wound registry: development and validation. Ann Emerg 
Med. 1995; 25(5):675-85. doi: 10.1016/S01960644(95)70183-4

3. Kaiser CW, Slowick T, Spurling KP, Friedman S. Retained foreign bodies. J Trauma. 1997; 43(1):107-11. doi: 10.1097/00005373-199707000-00025

4. Anderson MA, Newmeyer WL, Kilgore ES. Jr Diagnosis and treatment of retained foreign bodies in the hand. Am J Surg. 1982; 144(1):63-7. doi: 10.1016/00029610(82)90603-1. 